\title{
Crustal deformation analysis in Zagros and Makran zones, based on GPS permanent network data
}

\author{
Seyed Reza SAKHAEI*, Ghasem Ghorbani ROSTAM
}

Department of Physics, Sciences Faculty, Islamshahr Branch, Islamic Azad University, Islamshahr, Iran

\begin{abstract}
We present an analysis of strain based on the evaluation of crustal deformation in Zagros and Makran, which has implications in terms of the dynamics of the study area. We have used data from 17 permanent GPS stations of the Cartographic Centre of Iran spanning the period 2011-2013. The raw observed data were in RINEX format. The elements of strain tensor were calculated by a $2 \mathrm{D}$ isoparametric method and the inversion of strain equation. Then the dilatation (extension and compression) and shearing were obtained through the analysis of eigenvalue and eigenvector of tensors. In most cases compression has overcome the extension, which can be expected due to the convergence of the Arabia and Eurasia plates. The compression axis is nearly vertical along the Zagros causing reverse and thrust faults in Zagros. Due to the N-S trending of the SabzvaranJiroft-Kahnuj fault system and to the direction of compression and extension, the system will be of strike-slip mechanism. Sudden changes of shearing can be used to identify the strike-slip faults. As observed in this study, there were sudden changes in shearing of the Rafsanjan and Jiroft-Kahnuj faults. The $\mathrm{P} / \mathrm{T}$ axis rotates significantly in the Zagros-Makran transition zone. Moreover, the Makran's $\mathrm{P} / \mathrm{T}$ axis is smaller than the $\mathrm{P} / \mathrm{T}$ axis of Zagros, which demonstrates that the impact of the Arabian plate, moving towards Iran, is greater than the impact of the Indian subcontinent plate movement. The values of the counter-clockwise rotation rate at stations located east of the Zagros-Makran transition zone are higher than at other stations. Also the velocity vectors at stations were determined while using the software GAMIT/GLOBK.
\end{abstract}

Key words: crustal deformation analysis, strain, Zagros, Makran

\section{Introduction}

Iranian plateau as an active seismically area is located in the AlpineHimalayan belt. Accumulation of forces in Iran is through the Arabian plate moving toward north-east and the Indian subcontinent moving toward the

\footnotetext{
*corresponding author: e-mail: reza.sakhaei@srbiau.ac.ir
} 
north, which caused a seismic area. Understanding the elastic properties of the studying area and providing related seismotectonic model, are possible through the studying and understanding the basic parameters such as stress and strain fields of study area. In many studies, geodetic observations are used to determine the pattern of regional strain rate. Shen et al. (1996), Cai and Grafarend (2007), used a technique known as discretization. In the other way, inversion technique is used to determine the strain field (Spakman and Nyst, 2002). Allmendinger et al. (2007) used the nearest neighbour and weighted distance methods, to obtain the velocity fields.

The study area is one of the most complex tectonic regions of Iran (Figs. 1 and 2). Through the convergence of Arabia and Eurasia plates two different oceanic subduction zone (Makran) and collision zone (Zagros) in the south and southwest of Iran were created. In this research studying the crustal deformation of the Zagros and Makran through using the data recorded in 17 GPS permanent network stations (Fig. 1, Table 1) will be investigated. The contour map of results will be drawn and also the obtained results will be compared with the regional stress field and focal mechanisms of occurred earthquakes.

Table 1. Location of GPS permanent stations in this region.

\begin{tabular}{|c|c|c|c|}
\hline Station name & Latitude $\left({ }^{\circ} \mathbf{N}\right)$ & Longitude $\left({ }^{\circ} \mathbf{E}\right)$ & Height $(\mathbf{m})$ \\
\hline ABDN & 30.37783 & 48.21347 & -12.98 \\
\hline ANGN & 26.45720 & 57.89737 & 718.32 \\
\hline BAFT & 29.23915 & 56.58001 & 2275.75 \\
\hline BEBN & 30.60564 & 50.21693 & 301.98 \\
\hline BRBS & 27.20722 & 56.32058 & 4.75 \\
\hline CHBR & 25.27058 & 60.65112 & -19.73 \\
\hline DBST & 29.23770 & 57.33018 & 2633.19 \\
\hline FDNG & 30.82442 & 55.80831 & 1351.64 \\
\hline FHRJ & 28.93733 & 58.88126 & 666.71 \\
\hline GLMT & 27.48215 & 59.44850 & 363.14 \\
\hline JASC & 25.63752 & 57.76989 & -19.14 \\
\hline LAMD & 27.36365 & 53.20334 & 380.79 \\
\hline MHAN & 30.07158 & 57.28836 & 1873.25 \\
\hline SBAK & 30.14615 & 55.10749 & 1857.43 \\
\hline SHRZ & 29.54436 & 52.60258 & 1476.69 \\
\hline ZABL & 30.84127 & 61.71591 & 1152.28 \\
\hline ZRND & 30.83319 & 56.60769 & 1752.83 \\
\hline
\end{tabular}




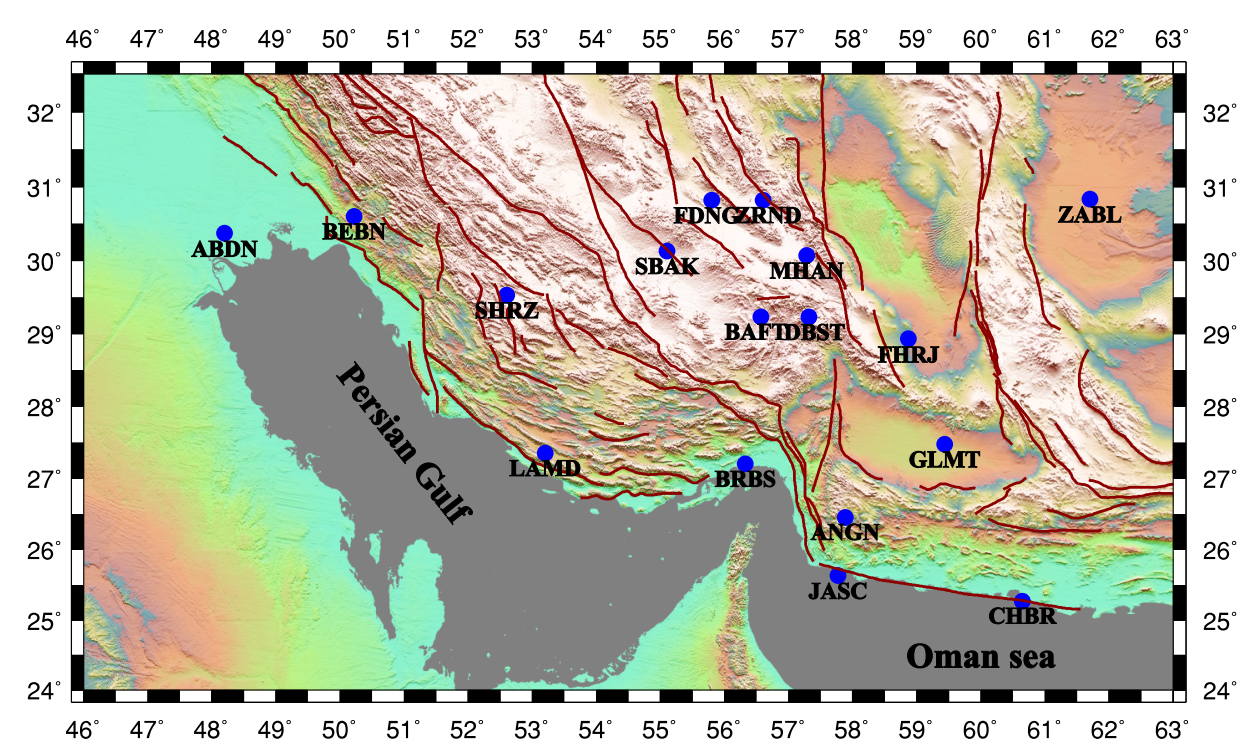

Fig. 1. Location of GPS permanent stations in south of Iran. The red lines represent main faults in this study area.

\section{Tectonic setting}

In the Strait of Hormuz in south of $\operatorname{Iran}\left(26.5^{\circ} \mathrm{N}\right.$ and $\left.56.5^{\circ} \mathrm{E}\right)$, the Arabian plate at avelocity of $23-25 \mathrm{~mm} / \mathrm{yr}$ (measured by GPS), converges with Eurasia (Bayer et al., 2003; McClusky et al., 2003; Vernant et al., 2004; Masson et al., 2007). Due to convergence of Arabia and Eurasia plates, two different zones have been created: continental collision (Zagros) and oceanic subduction (Makran) in the West and the East Strait of Hormuz, respectively. The continental part of Arabian plate and Eurasian plate have collided together and created Zagros fold and thrust belt with NW-SE trending. The East part of Arabian plate underthrusted to Iran plate and consequently the vast Makran accretionary wedge shaped with east-west trending (Byrne et al., 1992; McCall, 1997).

The shortening rate of Zagros is obtained about $10 \mathrm{~mm} / \mathrm{yr}$ with GPS measurement (Tatar et al., 2002, Vernant et al., 2004; Hessami et al., 2006). The total amount of shortening, in some studies is about $50 \mathrm{~km}$ (Molinaro et al., 2005) and according to other studies, it is estimated about $85 \mathrm{~km}$ (McQuarrie, 2004). Zagros is very active in terms of seismicity. More than 
50 percent of Iran's earthquakes which has been recorded by the global networks have occurred in Zagross (Mirzaei et al., 1998). Sudden change of seismicity can be seen from the severe seismicity in Zagros to partial rest in the West of Makran (Jackson and Mckenzie, 1984).

The rate of convergence in the Makran increases from West $(36.5 \mathrm{~mm} / \mathrm{yr}$ in the western border) to East ( $42 \mathrm{~mm} / \mathrm{yr}$ in the eastern border) (Demets et al., 1990; Zarifi, 2006). The rate of convergence in the Zagros is increased from Northwest to the Northeast. The rate of convergence in the transition from the Zagros collision zone to the Makran subduction zone, changes from $9 \pm 2 \mathrm{~mm} / \mathrm{yr}$ to $19 \pm 2 \mathrm{~mm} / \mathrm{yr}$ (Vernant et al., 2004; Masson et al., 2007).

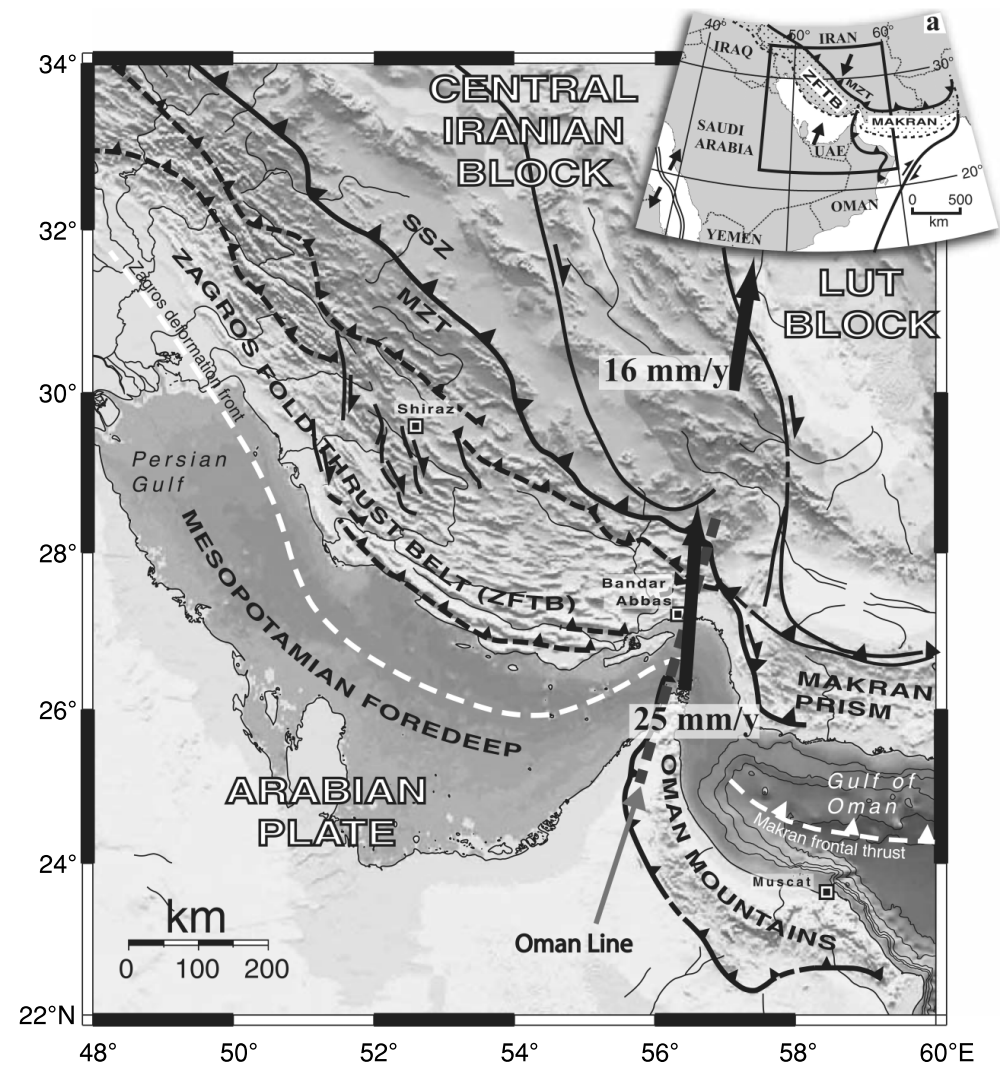

Fig. 2. Map of South Iran-North Arabia (Regard et al., 2010). The arrows represent the velocity relative to Eurasia (Vernantet al., 2004). MZT: Main Zagros Thrust; SSZ: Sanandaj-Sirjan Zone. 


\section{Determination of velocity vectors related to Eurasia and North Arabian plates}

Velocity vectors related to a fixed reference is interesting in geodesy. As discussed in section 2 (tectonic settings), the study area is influenced by the convergence of two plates. Therefore, the velocity vectors of the region relative to the two plates are investigated. The magnitude and azimuth of velocity vector for each GPS station is calculated by well-known GAMIT/GLOBK software related to Eurasia and North Arabian plates. To determine these vectors which are related to Eurasian plate, three IGS stations (TASH, POL2, KIT3) are considered as fix points and reference frame. This work is done also for North Arabian plate with four stations (HALY, RAMO, DRAG, BSHM) (Figs. 3 and 4). The magnitude and azimuth of velocity vectors are shown in Tables 2 and 3 (Figs. 5-8). $\mathrm{V}_{\mathrm{E}}$ and $\mathrm{V}_{\mathrm{N}}$ represent velocity vectors in East-West and North-South directions, respectively. $\pm \mathrm{V}_{\mathrm{E}}$ and $\pm \mathrm{V}_{\mathrm{N}}$ represent errors of velocity calculation. The maximum magnitude of velocity vector was observed in station BRBS with

Table 2. Azimuth and magnitude of velocity vector related to the Eurasia.

\begin{tabular}{|c|c|c|c|c|c|c|}
\hline $\begin{array}{c}\text { Station } \\
\text { name }\end{array}$ & $\begin{array}{c}\mathbf{V}_{\mathbf{E}} \\
(\mathbf{m m} / \mathbf{y r})\end{array}$ & $\begin{array}{c}\mathbf{V}_{\mathbf{N}} \\
(\mathbf{m} \mathbf{m} / \mathbf{y r})\end{array}$ & $\begin{array}{c} \pm \mathbf{V}_{\mathbf{E}} \\
(\mathbf{m m} / \mathbf{y r})\end{array}$ & $\begin{array}{c} \pm \mathbf{V}_{\mathbf{N}} \\
(\mathbf{m m} / \mathbf{y r})\end{array}$ & $\begin{array}{c}\text { Magnitude } \\
(\mathbf{m m} / \mathbf{y r})\end{array}$ & $\begin{array}{c}\text { Azimuth } \\
(\mathbf{d e g})\end{array}$ \\
\hline ABDN & 26.07 & 31.78 & 0.94 & 1.44 & 41.10 & 39.38 \\
\hline ANGN & 32.03 & 18.40 & 1.22 & 0.67 & 36.94 & 60.15 \\
\hline BAFT & 28.33 & 20.53 & 0.92 & 0.68 & 34.99 & 54.10 \\
\hline BEBN & 23.52 & 28.72 & 0.87 & 1.21 & 37.12 & 39.33 \\
\hline BRBS & 32.56 & 28.42 & 1.21 & 0.79 & 43.22 & 48.91 \\
\hline CHBR & 31.25 & 9.75 & 1.23 & 0.58 & 32.74 & 72.71 \\
\hline DBST & 33.13 & 16.48 & 0.98 & 0.72 & 37.00 & 63.58 \\
\hline FDNG & 19.92 & 9.40 & 0.90 & 0.85 & 22.03 & 64.77 \\
\hline FHRJ & 31.74 & 11.64 & 1.02 & 0.71 & 33.81 & 69.90 \\
\hline GLMT & 31.91 & 11.13 & 1.13 & 0.59 & 33.80 & 70.81 \\
\hline JASC & 29.15 & 17.17 & 1.29 & 0.64 & 33.83 & 59.53 \\
\hline LAMD & 28.52 & 25.96 & 1.31 & 1.08 & 38.57 & 47.71 \\
\hline MHAN & 29.42 & 20.89 & 0.83 & 0.64 & 36.08 & 54.65 \\
\hline SBAK & 26.81 & 20.83 & 0.85 & 0.78 & 33.95 & 52.18 \\
\hline SHRZ & 25.7 & 21.83 & 0.95 & 0.98 & 33.72 & 49.68 \\
\hline ZABL & 30.57 & 9.16 & 0.62 & 0.35 & 31.91 & 73.36 \\
\hline ZRND & 27.38 & 19.60 & 0.79 & 0.70 & 33.67 & 54.43 \\
\hline
\end{tabular}


Sakhaei S. R., Rostam G. G.: Crustal deformation analysis in Zagros ...

$(61-81)$

Table 3. Azimuth and magnitude of velocity vector related to the North Arabian plate.

\begin{tabular}{|c|c|c|c|c|c|c|}
\hline $\begin{array}{c}\text { Station } \\
\text { name }\end{array}$ & $\begin{array}{c}\mathbf{V}_{\mathbf{E}} \\
(\mathbf{m m} / \mathbf{y r})\end{array}$ & $\begin{array}{c}\mathbf{V}_{\mathbf{N}} \\
(\mathbf{m m} / \mathbf{y r})\end{array}$ & $\begin{array}{c} \pm \mathbf{V}_{\mathbf{E}} \\
(\mathbf{m m} / \mathbf{y r})\end{array}$ & $\begin{array}{c} \pm \mathbf{V}_{\mathbf{N}} \\
(\mathbf{m m} / \mathbf{y r})\end{array}$ & $\begin{array}{c}\text { Magnitude } \\
(\mathbf{m m} / \mathbf{y r})\end{array}$ & $\begin{array}{c}\text { Azimuth } \\
(\mathbf{d e g})\end{array}$ \\
\hline ABDN & 30.37 & 37.65 & 0.5 & 0.72 & 48.37 & 38.89 \\
\hline ANGN & 50.42 & 40.88 & 1.34 & 1.58 & 64.91 & 50.97 \\
\hline BAFT & 38.74 & 41.63 & 1.20 & 1.28 & 56.87 & 42.94 \\
\hline BEBN & 28.01 & 38.05 & 0.61 & 0.81 & 47.25 & 36.36 \\
\hline BRBS & 47.95 & 48.02 & 1.21 & 1.42 & 67.86 & 44.96 \\
\hline CHBR & 55.06 & 37.75 & 1.63 & 1.91 & 66.76 & 55.57 \\
\hline DBST & 43.94 & 39.16 & 1.34 & 1.38 & 58.86 & 48.29 \\
\hline FDNG & 26.01 & 29.47 & 1.22 & 1.25 & 39.31 & 41.43 \\
\hline FHRJ & 44.26 & 37.71 & 1.53 & 1.54 & 58.15 & 49.57 \\
\hline GLMT & 48.73 & 37.77 & 1.57 & 1.67 & 61.65 & 52.22 \\
\hline JASC & 49.56 & 38.85 & 1.29 & 1.62 & 62.97 & 51.91 \\
\hline LAMD & 41.45 & 39.35 & 0.98 & 1.23 & 57.15 & 46.49 \\
\hline MHAN & 38.08 & 43.85 & 1.29 & 1.30 & 58.08 & 40.97 \\
\hline SBAK & 34.25 & 39.22 & 1.06 & 1.14 & 52.07 & 41.13 \\
\hline SHRZ & 33.40 & 35.08 & 0.80 & 0.98 & 48.44 & 43.60 \\
\hline ZABL & 39.42 & 42.52 & 1.81 & 1.56 & 57.98 & 42.83 \\
\hline ZRND & 33.77 & 41.31 & 1.24 & 1.24 & 53.36 & 39.27 \\
\hline
\end{tabular}

values 43.22 and $67.86 \mathrm{~mm} / \mathrm{yr}$ related to the plates of Eurasia and North Arabian, respectively. And the minimum magnitude of velocity vector was obtained in station FDNG with values 22.03 and $39.31 \mathrm{~mm} / \mathrm{yr}$ related to the plates of Eurasia and North Arabian, respectively. In the convergence with the Eurasia plate, ZABL and BEBN stations have the highest $\left(73.36^{\circ}\right)$ and the lowest $\left(39.33^{\circ}\right)$ azimuth, respectively. Also, CHBR and BEBN stations have the highest $\left(55.57^{\circ}\right)$ and the lowest $\left(36.36^{\circ}\right)$ Azimuth in divergence with the Northern Arabian Plate, respectively. The average error in the calculation of the velocity vector of the Eurasian and North Arabia has been set 0.92 and $1.31 \mathrm{~mm} / \mathrm{yr}$, respectively.

\section{Strain analysis}

In this study, the 2-D isoparametric method is used to obtain the strain tensor. This method utilizes the relative distance analysis between a point and its adjacent area before and after deformation and acquires a strain tensor for each point (GPS station). Mathematically, the strain is the gra- 


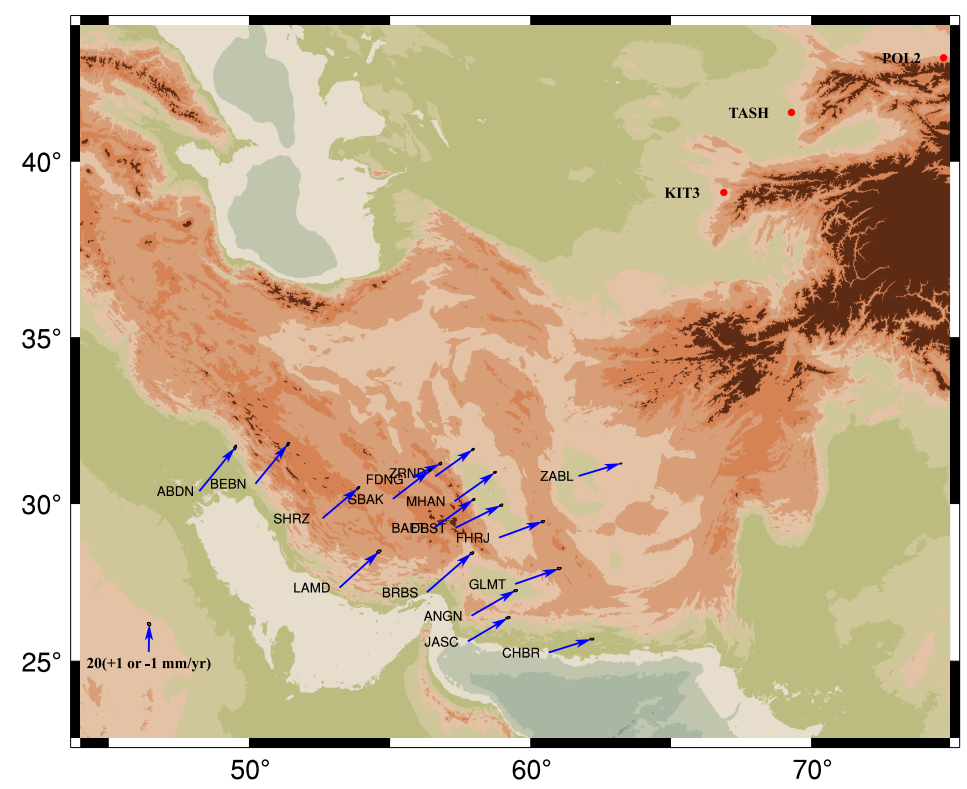

GMT 2020 Mar 30 21:26:33

Fig. 3. Velocity vectors related to the Eurasia plate. Red circles are reference stations in the Eurasia plate.

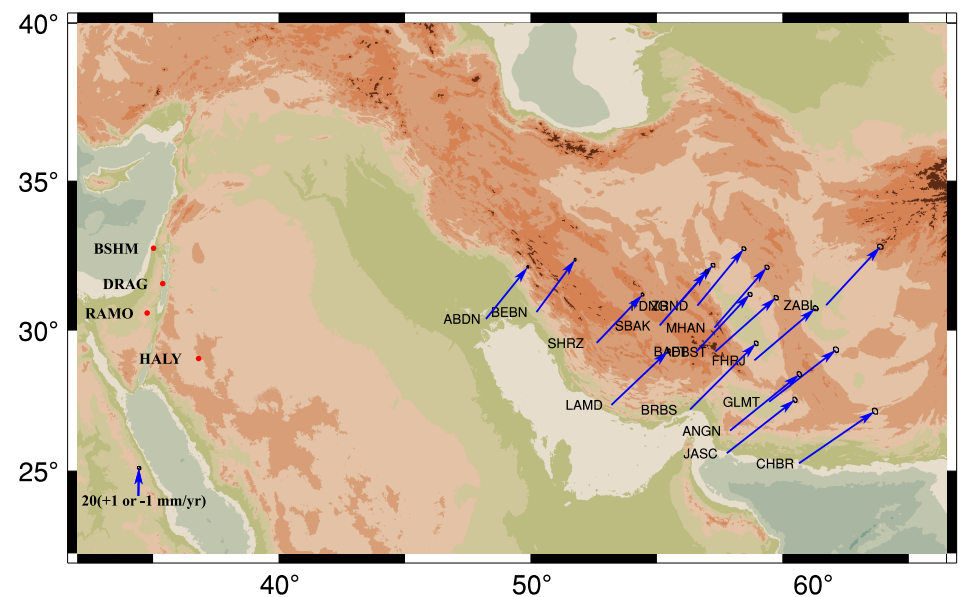

GMT2 2020 Mar 30 21:26:42

Fig. 4. Velocity vectors related to the North Arabian plate. Red circles are reference stations in the North Arabian plate. 


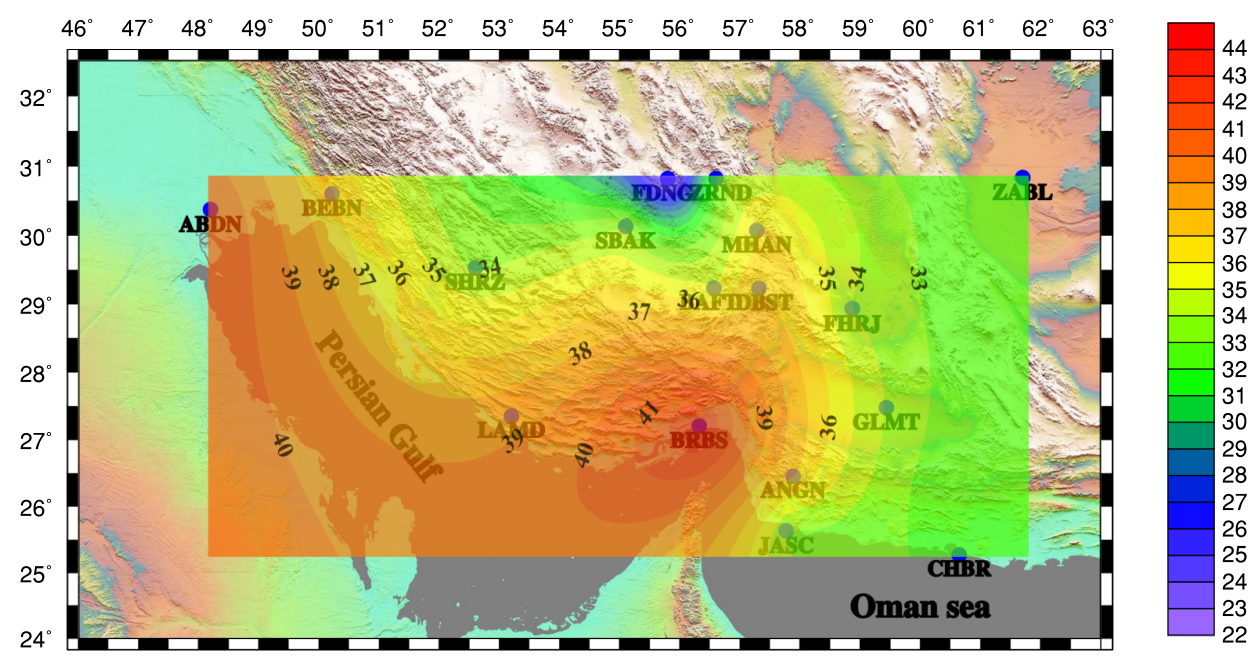

Fig. 5. Contour map of magnitude of velocity vectors related to the Eurasia plate (mm/yr).

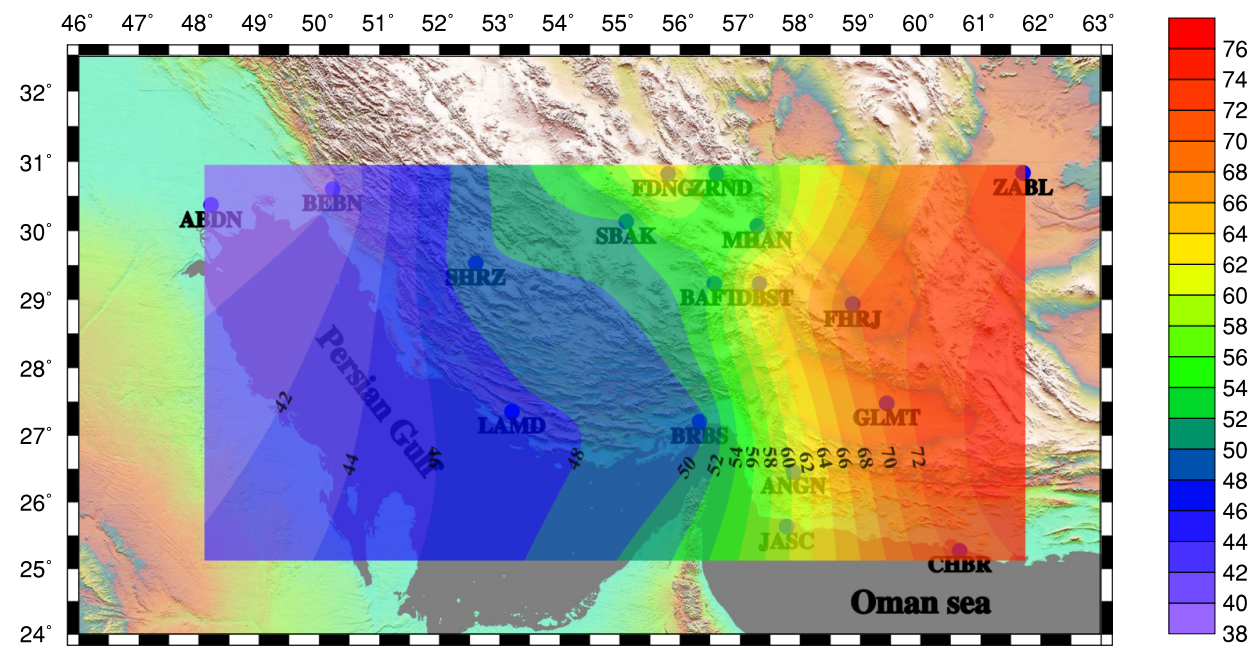

Fig. 6. Contour map of azimuth of velocity vectors related to the Eurasia plate (deg).

dient of the displacement field, that is, the displacement of two points at a differential distance. In the study of deformation using strain calculations, because the dependence on the coordinate system is eliminated, its results can be trusted more than other methods (Vanicek and Krakiwsky, 1986). 


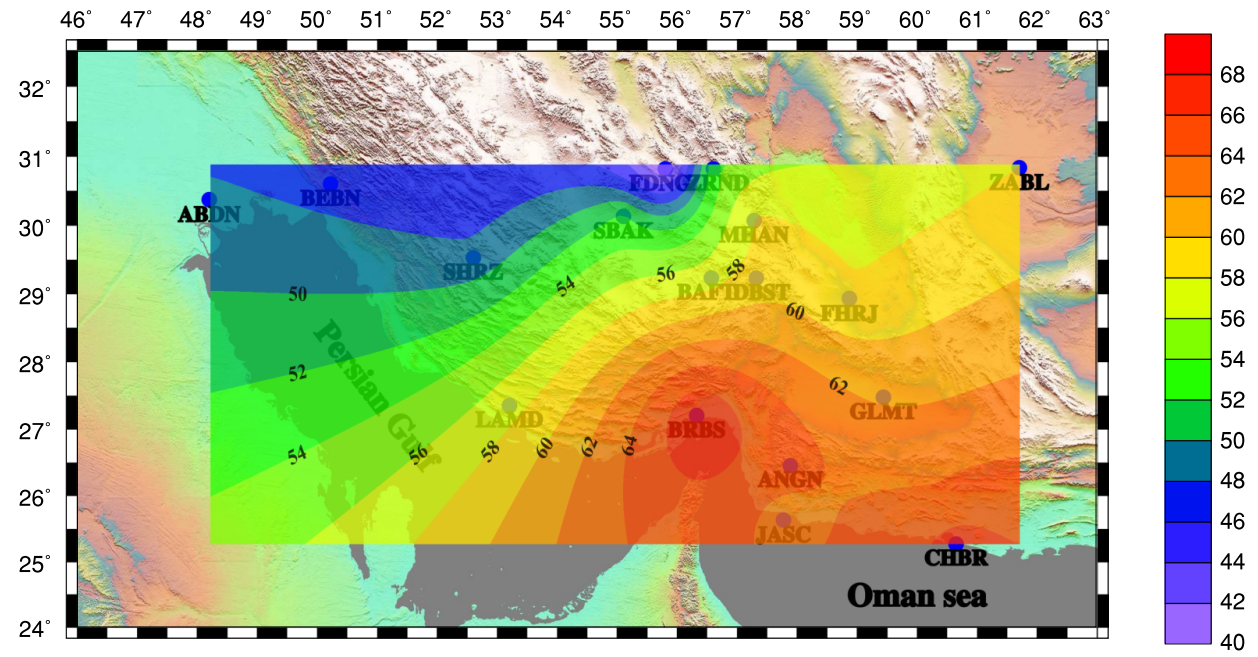

Fig. 7. Contour map of magnitude of velocity vectors related to the North Arabian plate $(\mathrm{mm} / \mathrm{yr})$.

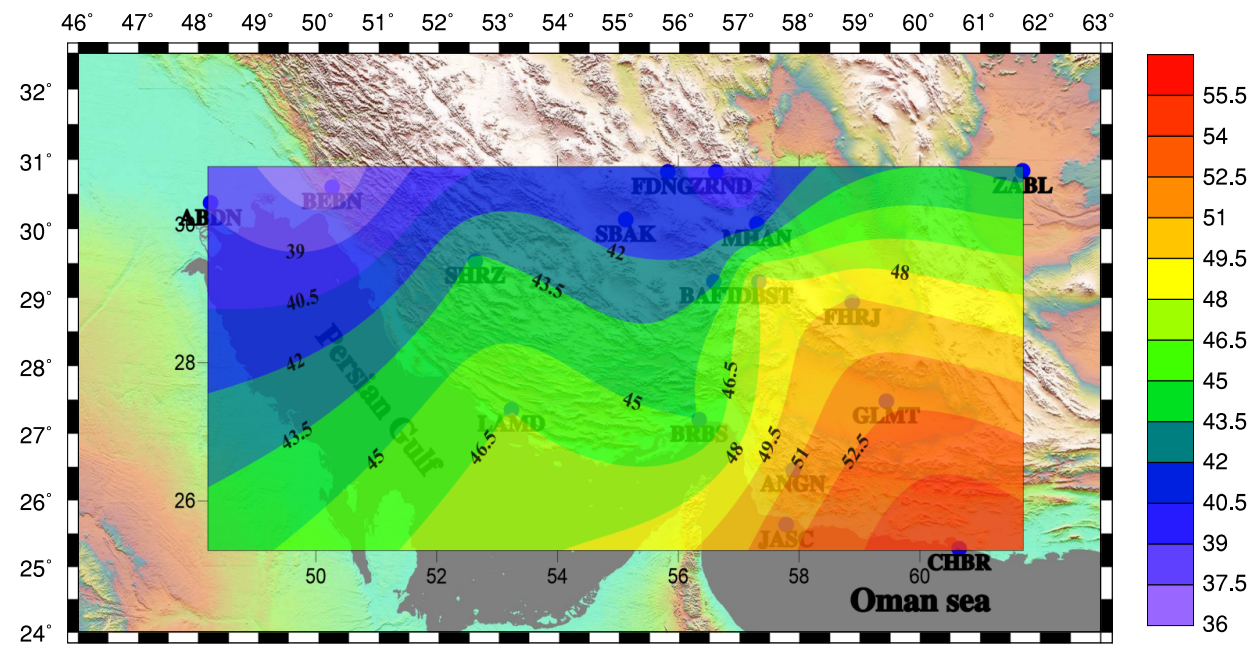

Fig. 8. Contour map of azimuth of velocity vectors related to the North Arabian plate (deg).

We consider two adjacent points of $\underline{a}$ and $\underline{b}$, so that their positions in the two-dimensional coordinate system before and after deformation are $(x, y)$ and $\left(x+x^{\prime}, y+y^{\prime}\right)$, respectively. If the vector displacement of point 
$\underline{a}$ caused by deformation, is $(u, v)$, then the displacement vector of point $\underline{b}$ can be written in the form of $\left(u+u^{\prime}, v+v^{\prime}\right)$. Values of $u^{\prime}$ and $v^{\prime}$ by using Taylor expansion and elimination of higher order sentences are calculated as follows:

$u^{\prime}=e_{x x} x^{\prime}+\frac{1}{2} \gamma_{x y} y^{\prime}-\omega y^{\prime}$,

$v^{\prime}=\frac{1}{2} \gamma_{x y} x^{\prime}+e_{y y} y^{\prime}+\omega x^{\prime}$,

where:

$e_{x x}=\frac{\partial u}{\partial x}, \quad e_{y y}=\frac{\partial v}{\partial y}, \quad \gamma_{x y}=\gamma_{y x}=\frac{\partial u}{\partial y}+\frac{\partial v}{\partial x}, \quad \omega=\frac{1}{2}\left(\frac{\partial v}{\partial x}-\frac{\partial u}{\partial y}\right)$,

In this equation $e_{x x}, e_{y y}, \gamma_{x y}$ and $\gamma_{y x}$ are elements of strain matrix.

To calculate the elements of strain matrix, we can use equations of the lengths of two adjacent points (before and after of deformation) and eliminating the sentences containing the second power and by multiplying derivations at each other:

$\varepsilon=e_{x x} \cos ^{2} \alpha+\gamma_{x y} \sin \alpha \cos \alpha+e_{y y} \sin ^{2} \alpha$,

where the angle between the vector of $r$ and $x$-axis is called $\alpha$.

The amount of $\varepsilon$ is determined by calculating the difference between the displacement of two points before and after deformation. Finally, by knowing the angle $\alpha$ and strain $\varepsilon$ we will find three unknown parameters that are strain matrix elements. Since we measure the displacement in relation to several adjacent stations for any stations, so the relationship (4) can be written in matrix form $d=G m$, where $d$ is called a data matrix or the information. Also, the matrix $G$ is a matrix from the order of $i * 3$ ( $i=$ number of station). If $i$ equals 3 , we have three equations with three unknown parameters. And if you have more than three stations, the problem will be solved by using generalized linear inversion (Lay and Wallace, 1995):

$m=\left(G^{T} G\right)^{-1} G^{T} d$.

To find the directions of maximum and minimum extensions, we can derive the equation (4) to $\alpha$ and equal it to zero. Directions that satisfy the following relation are the maximum and minimum angles of extension and their values are eigenvalues of strain tensor $\left(\lambda_{\max }, \lambda_{\min }\right)$ : 
$\tan 2 \alpha=\frac{\gamma_{x y}}{e_{x x}-e y y}$.

Through splitting the strain tensor into two symmetric and antisymmetric parts, it can be written as:

$\varepsilon=\frac{1}{2}\left(\varepsilon+\varepsilon^{T}\right)+\frac{1}{2}\left(\varepsilon-\varepsilon^{T}\right)=\varepsilon_{s}+\varepsilon_{a s}$,

where $\varepsilon_{s}$ and $\varepsilon_{a s}$ are symmetric strain tensors (represent deformation of the object) and antisymmetric strain tensor (represents rotation of the object), respectively.

$\varepsilon_{s}=\left[\begin{array}{cc}e_{x x} & \frac{1}{2}\left(e_{x y}+e_{y x}\right) \\ \frac{1}{2}\left(e_{y x}+e_{x y}\right) & e_{y y}\end{array}\right]$,

$\varepsilon_{a s}=\left[\begin{array}{cc}0 & -\frac{1}{2}\left(e_{y x}-e_{x y}\right) \\ \frac{1}{2}\left(e_{y x}-e_{x y}\right) & 0\end{array}\right]$.

Moreover, by defining two quantities of elongation $(\Delta)$ and shearing $(\gamma)$ we can interpret a more tangible to the strain in the desired station:

$\Delta=\lambda_{\max }+\lambda_{\min }=e_{x x}+e_{y y}$,

$\gamma=\lambda_{\max }-\lambda_{\min }=\sqrt{\left(e_{x x}-e_{y y}\right)^{2}+4 e_{x y}^{2}}$.

Positive and negative values of elongation are referred to as expansion (stretching) and contraction (compression) of surface, respectively. Shearing gives maximum amount of change in direction, which is non-isotropic deformation property.

\subsection{Calculation of strain tensor}

To determine the strain tensor in each GPS permanent station in the south of Iran (around Zagros and Makran), the observed raw data (position) were used in the RINEX (Receiver Independent Exchange) format from 2011 to 2013. RINEX is a data interchange format for raw data (usually position and speed) that allows the user to post-process the received data to produce a more accurate result. To determine the coordinates of stations, the data 
processed in NGS site (http://www.ngs.noaa.gov/OPUS/). The On-line Positioning User Service (OPUS) allows users to submit their GPS data files (for each selected day) to NGS, where the data are processed to determine position coordinates using NGS computers and software. OPUS is based on the average of three distinct single-baseline solutions computed using double-differenced, dual-frequency carrier-phase measurements using PAGES software. The selected Continuously Operating Reference Stations (CORS) sites may not be the nearest to the user location but are chosen by a few criteria, such as: distance, number of observations, site stability, etc. A good OPUS run is defined as a solution which used 90 percent or more of the observations, fixed at least 50 percent of the ambiguities, and the overall RMS did not exceed $3 \mathrm{~cm}$. The estimated position is reported back to the user via email in International Terrestrial Reference Frame (ITRF) coordinate systems (Kashani et al., 2008). On the other hand, we know that ITRF uses the IGS reference stations (with a certain location). Then, the OPUS results (position for each day) are used as input data and the strain tensors were calculated by using the above formulas. We obtained the strain with the displacement of the points at the beginning and end of the time period. To avoid possible positioning errors, we used an average of 3 to 5 days (for each station) at the beginning and the end. The elements of strain tensors and distance between GPS stations and IGS reference stations are represented in Table 4.

Table 4. Elements of strain tensor ( $\mu$-strain/year) and distance with IGS stations.

\begin{tabular}{|c|c|c|c|c|c|}
\hline $\begin{array}{c}\text { Station } \\
\text { name }\end{array}$ & $e_{x x}$ & $e_{x y}$ & $e_{y y}$ & $\begin{array}{c}\text { IGS Reference } \\
\text { stations }\end{array}$ & $\begin{array}{c}\text { Distance } \\
(\mathrm{km})\end{array}$ \\
\hline \multirow{3}{*}{$\mathrm{ABDN}$} & \multirow{3}{*}{0.0331} & \multirow{3}{*}{0.0677} & \multirow{3}{*}{0.0148} & ISKU & 328.178 \\
\hline & & & & ISNA & 410.024 \\
\hline & & & & ISBA & 485.219 \\
\hline \multirow{3}{*}{ ANGN } & \multirow{3}{*}{0.0070} & \multirow{3}{*}{-0.0351} & \multirow{3}{*}{-0.0125} & TEHN & 1198.360 \\
\hline & & & & ISKU & 1346.579 \\
\hline & & & & ISBA & 1501.967 \\
\hline \multirow{3}{*}{ BAFT } & \multirow{3}{*}{0.0713} & \multirow{3}{*}{0.0440} & \multirow{3}{*}{-0.0101} & YILB & 782.389 \\
\hline & & & & TEHN & 868.760 \\
\hline & & & & ISKU & 1116.015 \\
\hline \multirow{3}{*}{ BEBN } & \multirow{3}{*}{0.0337} & \multirow{3}{*}{0.0683} & \multirow{3}{*}{-0.0103} & ISKU & 468.267 \\
\hline & & & & TEHN & 574.096 \\
\hline & & & & ISBA & 624.393 \\
\hline
\end{tabular}


Table 4. Continued from the previous page.

\begin{tabular}{|c|c|c|c|c|c|}
\hline $\begin{array}{c}\text { Station } \\
\text { name }\end{array}$ & $e_{x x}$ & $e_{x y}$ & $e_{y y}$ & $\begin{array}{c}\text { IGS Reference } \\
\text { stations }\end{array}$ & $\begin{array}{c}\text { Distance } \\
(\mathrm{km})\end{array}$ \\
\hline \multirow{3}{*}{ BRBS } & \multirow{3}{*}{-0.0059} & \multirow{3}{*}{-0.0591} & \multirow{3}{*}{-0.0530} & YILB & 556.369 \\
\hline & & & & ISBS & 906.715 \\
\hline & & & & TEHN & 1052.412 \\
\hline \multirow{3}{*}{ CHBR } & \multirow{3}{*}{0.0164} & \multirow{3}{*}{-0.0140} & \multirow{3}{*}{-0.0079} & TEHN & 1455.971 \\
\hline & & & & KIT3 & 1639.252 \\
\hline & & & & ISKU & 1647.212 \\
\hline \multirow{3}{*}{ DBST } & \multirow{3}{*}{0.0710} & \multirow{3}{*}{0.1811} & \multirow{3}{*}{0.0595} & TEHN & 910.576 \\
\hline & & & & ISKU & 1157.674 \\
\hline & & & & ISBA & 1305.913 \\
\hline \multirow{3}{*}{ FDNG } & \multirow{3}{*}{0.1055} & \multirow{3}{*}{-0.0329} & \multirow{3}{*}{-0.3117} & TEHN & 682.170 \\
\hline & & & & ISKU & 965.217 \\
\hline & & & & ISBA & 1107.170 \\
\hline \multirow{3}{*}{ FHRJ } & \multirow{3}{*}{0.0105} & \multirow{3}{*}{-0.0621} & \multirow{3}{*}{-0.0281} & YILB & 797.384 \\
\hline & & & & TEHN & 1031.264 \\
\hline & & & & ISBS & 1084.635 \\
\hline \multirow{3}{*}{ GLMT } & \multirow{3}{*}{-0.0080} & \multirow{3}{*}{-0.0174} & \multirow{3}{*}{-0.0083} & TEHN & 1190.221 \\
\hline & & & & ISBS & 1181.107 \\
\hline & & & & ISKU & 1424.556 \\
\hline \multirow{3}{*}{ JASC } & \multirow{3}{*}{0.0363} & & & YIBL & 417.744 \\
\hline & & -0.0461 & -0.0673 & ISKU & 1386.915 \\
\hline & & & & ISBA & 1543.421 \\
\hline & & & & ISKU & 912.130 \\
\hline LAMD & 0.0394 & 0.0289 & -0.0461 & TEHN & 940.121 \\
\hline & & & & ISER & 1303.952 \\
\hline & & & & TEHN & 935.694 \\
\hline MHAN & -0.0103 & 0.0195 & 0.0553 & ISKU & 1123.880 \\
\hline & & & & $\begin{array}{l}\text { ISNA } \\
\end{array}$ & 1250.794 \\
\hline & & & & TEHN & 709.274 \\
\hline SBAK & 0.0211 & -0.0553 & -0.1427 & ISKU & 921.780 \\
\hline & & & & ISBA & 1069.495 \\
\hline & & & & ISBS & 475.270 \\
\hline SHRZ & -0.0038 & -0.0476 & -0.0633 & ISKU & 726.350 \\
\hline & & & & ISNA & 834.942 \\
\hline & & & & KIT3 & 1032.549 \\
\hline ZABL & -0.0106 & -0.0362 & -0.0007 & TEHN & 1104.921 \\
\hline & & & & ISKU & 1514.722 \\
\hline & & & & TEHN & 729.206 \\
\hline ZRND & 0.0561 & -0.0747 & -0.1051 & ISKU & 1039.213 \\
\hline & & & & ISBA & 1179.708 \\
\hline
\end{tabular}




\subsection{Calculation of dilatation and shearing}

By analysis of eigenvalues and eigenvectors of matrix, we will achieve some important results. Summation and minus of the maximum and the minimum of eigenvalues are dilatation and shearing in each station, respectively. Moreover, eigenvalues determine direction of stretching and compression (Fig. 11). These values were calculated for the study of the study area and are represented in Table 5. Maximum compression (negative dilatation) and maximum stretching (positive dilatation) are $-0.2062 \times 10^{-6}$ and $0.1305 \times 10^{-6}$ in the stations FDNG and DBST, respectively. Maximum and minimum shearing are also obtained in the stations FDNG and GLMT with values of $0.4224 \times 10^{-6}$ and $0.0349 \times 10^{-6}$, respectively. Figs. 9 and 10 represent contour maps of dilatation and shearing.

Table 5. Eigenvalue, dilatation and shearing in the each stations ( $\mu$-strain/year).

\begin{tabular}{|c|c|c|c|c|}
\hline Station name & l_max & l_min & Dilatation & Shearing \\
\hline ABDN & 0.0923 & -0.0444 & 0.0479 & 0.1367 \\
\hline ANGN & 0.0337 & -0.0392 & -0.0055 & 0.0729 \\
\hline BAFT & 0.0905 & -0.0293 & 0.0612 & 0.1198 \\
\hline BEBN & 0.0835 & -0.0601 & 0.0234 & 0.1436 \\
\hline BRBS & 0.0342 & -0.0932 & -0.0590 & 0.1274 \\
\hline CHBR & 0.0228 & -0.0143 & 0.0085 & 0.0372 \\
\hline DBST & 0.2465 & -0.1160 & 0.1305 & 0.3625 \\
\hline FDNG & 0.1081 & -0.3143 & -0.2062 & 0.4224 \\
\hline FHRJ & 0.0562 & -0.0738 & -0.0176 & 0.1301 \\
\hline GLMT & 0.0093 & -0.0256 & -0.0163 & 0.0349 \\
\hline JASC & 0.0539 & -0.0849 & -0.0310 & 0.1388 \\
\hline LAMD & 0.0483 & -0.0550 & -0.0067 & 0.1033 \\
\hline MHAN & 0.0607 & -0.0157 & 0.0450 & 0.0765 \\
\hline SBAK & 0.0381 & -0.1597 & -0.1216 & 0.1978 \\
\hline SHRZ & 0.0226 & -0.0897 & -0.0671 & 0.1123 \\
\hline ZABL & 0.0308 & -0.0421 & -0.0113 & 0.0730 \\
\hline ZRND & 0.0854 & -0.1344 & -0.0490 & 0.2198 \\
\hline
\end{tabular}

\subsection{Rotation rate}

The rotation rates are negative values in all stations. So rotation isn't clockwise. Table 6 and Fig. 12 represent values of rotation rate and its 


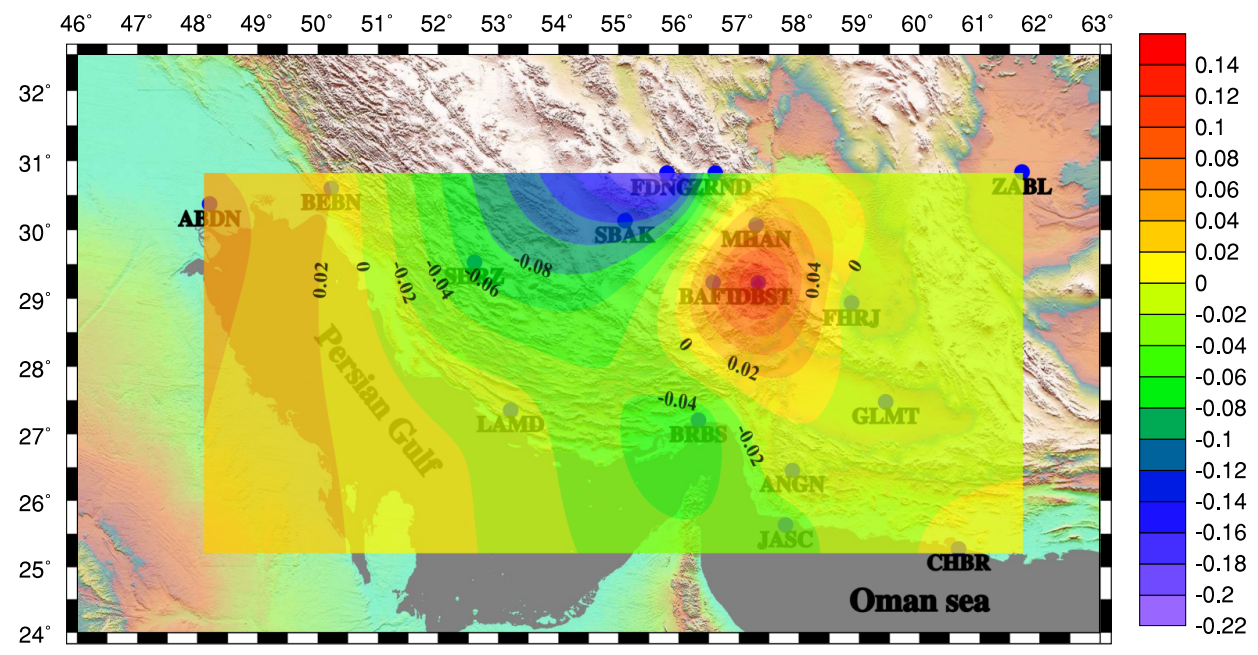

Fig. 9. Contour map of dilatation for study region ( $\mu$-strain/year).

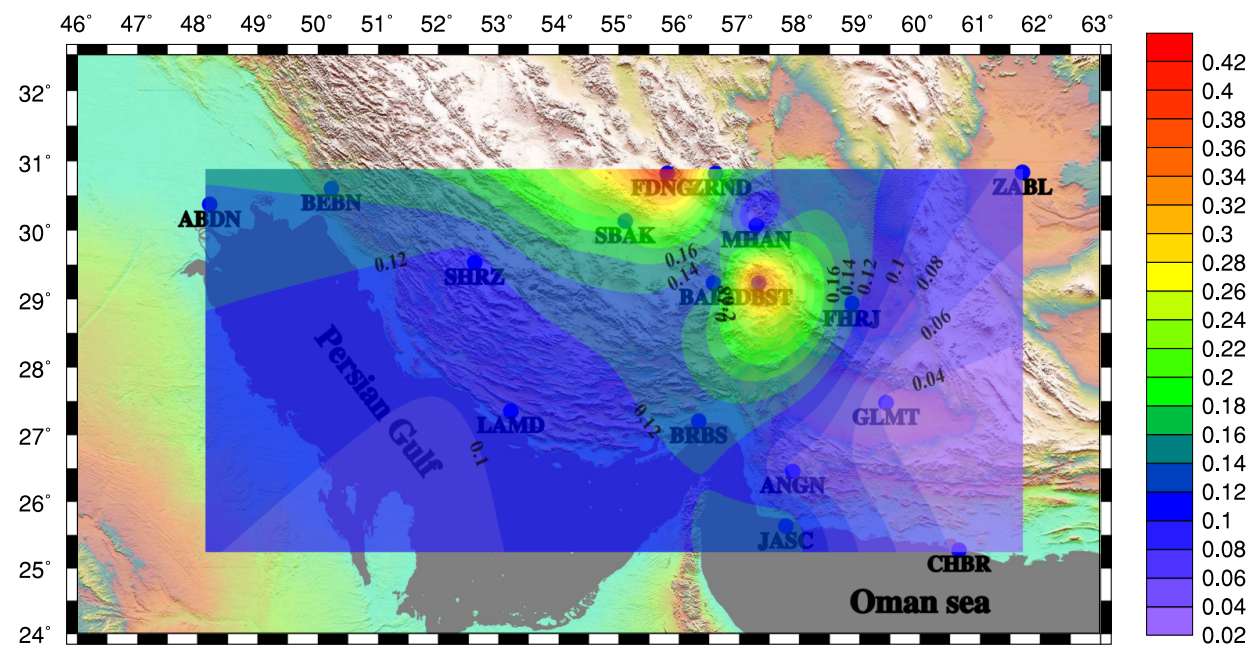

Fig. 10. Contour map of shearing for study region ( $\mu$-strain/year).

contour map, respectively. Maximum values of rotation rates are 6.09 and 5.46 in the stations CHBR and DBST, respectively. Stations LAMD and FDNG have minimum rotation rates (2.39 and 2.9, respectively). 


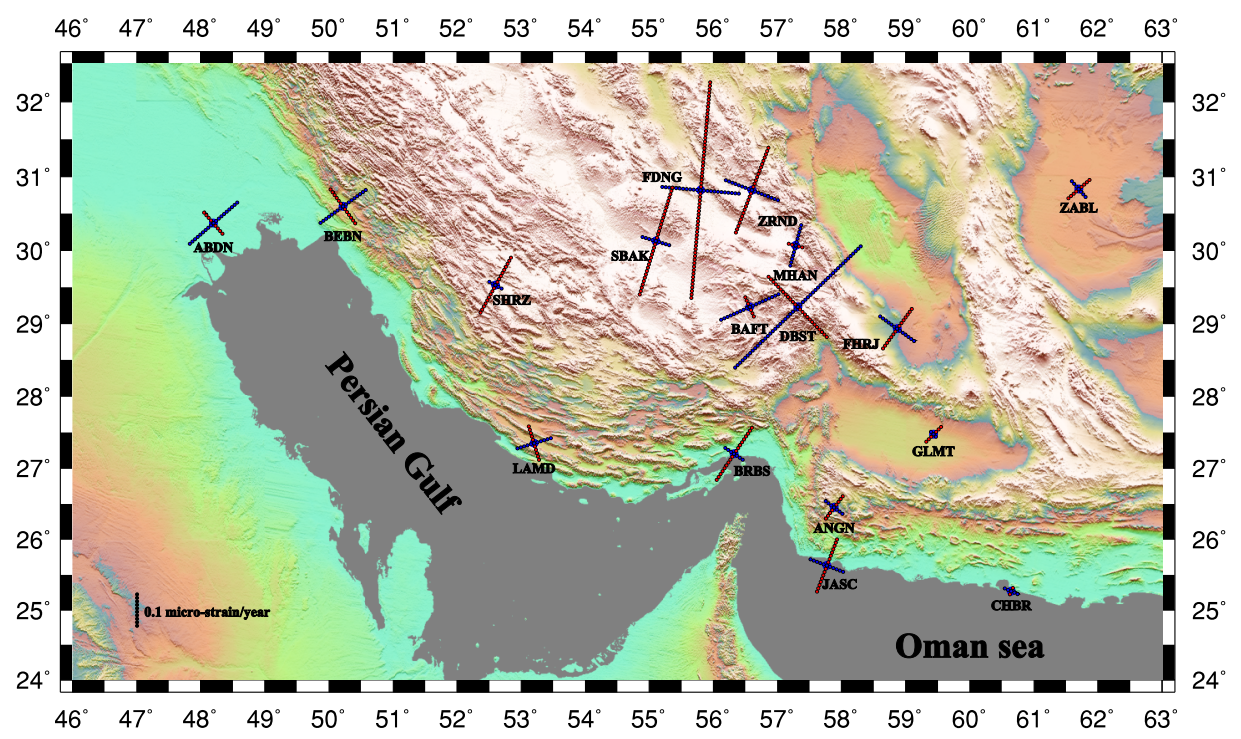

Fig. 11. Axis of stretching (blue) and compression (red).

Table 6. Values of anti-clockwise rotation rate $\left(\times 10^{-7} \mathrm{deg} / \mathrm{yr}\right)$.

\begin{tabular}{|c|c|}
\hline Station & Rotation rate \\
\hline ABDN & 3.43 \\
\hline ANGN & 4.73 \\
\hline BAFT & 4.33 \\
\hline BEBN & 4.72 \\
\hline BRBS & 5.43 \\
\hline CHBR & 6.09 \\
\hline DBST & 5.46 \\
\hline FDNG & 2.90 \\
\hline FHRJ & 5.21 \\
\hline GLMT & 4.72 \\
\hline JASC & 4.72 \\
\hline LAMD & 2.39 \\
\hline MHAN & 4.30 \\
\hline SBAK & 4.43 \\
\hline SHRZ & 4.28 \\
\hline ZABL & 4.47 \\
\hline ZRND & 3.90 \\
\hline
\end{tabular}




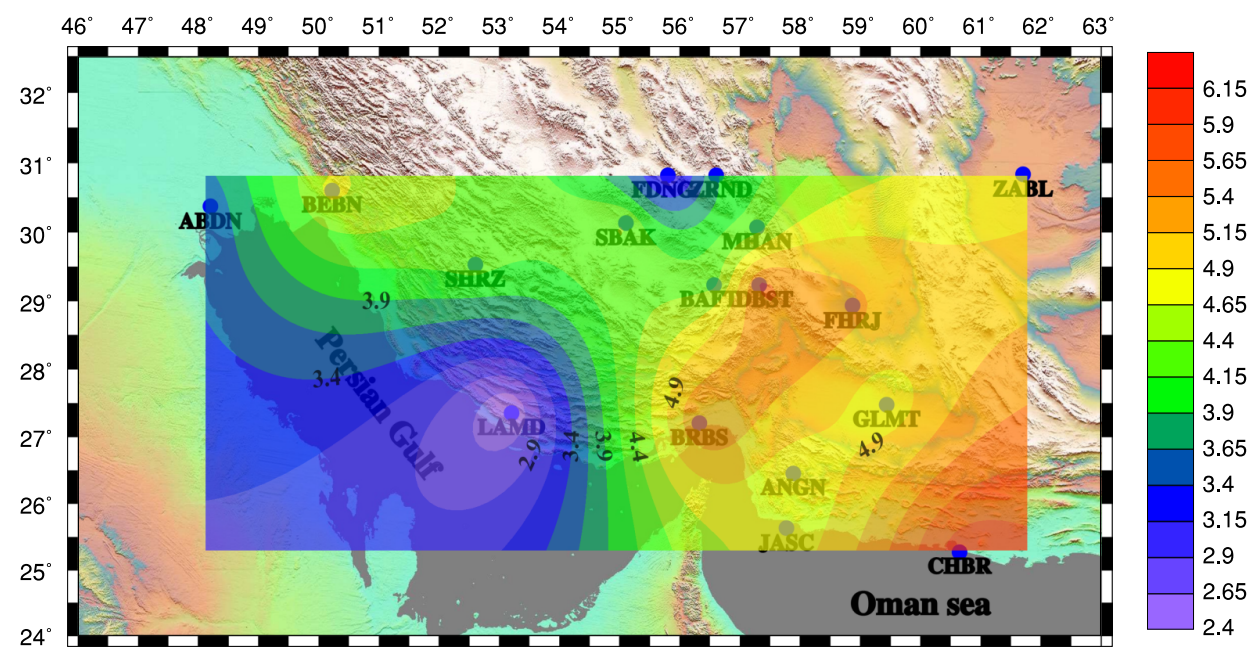

Fig. 12. The contour map of rotation rate $\left(\times 10^{-7} \mathrm{deg} / \mathrm{yr}\right)$.

\section{Surveying the correctness of results}

The condition number is a parameter that represents sensitivity values of function related to input error. This number is obtained from dividing maximum singular value to minimum singular value of Kernel matrix. This value is 1 to $\infty$. Value 1 and $\infty$ show the best and the worst condition, respectively. So, if this number is low, we can estimate the solution (model) more carefully. In this study, the condition numbers are low, so inversion problem is in good condition and has stable solution. Maximum values obtained in ABDN and SHRZ stations with values 13.31 and 8.52, respectively (total average is 4.7). In other words, there is the best (stable) condition in the BAFT station with the condition number of 1.96. Other values are shown in Table 7.

\section{Discussion and conclusion}

As mentioned before, the purpose of this study was the investigation of crustal deformation in the Zagros collision zone and the Makran subduction zone with geodetic data. To achieve this purpose, the data of 17 GPS 
Table 7. condition numbers in the inversion calculation.

\begin{tabular}{|c|c|}
\hline Station & Condition number \\
\hline ABDN & 13.31 \\
\hline ANGN & 2.13 \\
\hline BAFT & 1.96 \\
\hline BEBN & 6.74 \\
\hline BRBS & 3.09 \\
\hline CHBR & 4.47 \\
\hline DBST & 4.39 \\
\hline FDNG & 3.64 \\
\hline FHRJ & 2.75 \\
\hline GLMT & 4.83 \\
\hline JASC & 2.52 \\
\hline LAMD & 5.69 \\
\hline MHAN & 2.18 \\
\hline SBAK & 4.01 \\
\hline SHRZ & 8.52 \\
\hline ZABL & 5.96 \\
\hline ZRND & 4.42 \\
\hline
\end{tabular}

permanent stations with 2-D isoparametric method were used. The results were analyzed with condition number of kernel matrix. Because of small size of amount, it can be said that the results have good stability and are great to be trusted.

In 11 stations, dilation values are indications of compression domination in the region. Only in 6 stations, values of stretching are dominant on the compression. This is convincing due to the convergence of Arabian and Eurasian plates on one hand and on the other hand the Indian subcontinent towards Eurasia is justified. The compression axis is nearly vertical along the Zagros and will be a reason to reverse and thrust faulting in the Zagros. But according to the North-South trending of Sbzvaran-JiroftKahnuj and the compression and extensional axis direction, the mechanism of this system will be strike-slip.

According to the shearing contour map in two areas the amount of shearing which is related to the other parts are increased significantly. Since the shearing is defined as the maximum change in along, it is expected to be big strike-slip fault in these two points. Referring to the map of active faults 
of Iran, these points are on the surrounding of Jiroft-Kahnuj and Rafsanjan faults, respectively. So sudden changes in the shearing can be used as detection of strike-slip faults.

The axes of extension/compression in the Zagros-Makran transition zone have rotated significantly, and it seems to be in communication with the sensitive change of the fault trending from Zagros toward the transition zone and different faulting to the Zagros (in terms of trending and mechanism) is justified on these rotations. Also, this axis in the Makran are smaller than the Zagros, which demonstrates the influence of the Arabian plate moving toward Iran is more than the moving impact of the Indian subcontinent plate. It can be concluded that the values of rotation rate of stations located in East of Zagros-Makran transition zone are larger than western stations.

The achieved velocity vectors towards the Eurasian plate have the northeast direction, which are in compliance with Iran and Eurasian convergence. The displacement rate at the BABS station (in the vicinity of the ZMP fault system and Oman Line), both in terms of magnitude and azimuth is larger than the other stations. This represents a significant change in the strain field in the Zagros-Makran transition zone towards its surrounding areas.

According to the Zagros faults (NW-SE) and Zendan-Minab-Palami fault system trending (in the Zagros-Makran transition zone) and the direction of velocity vectors which are obtained in this study, the mechanism of compression for Zagros faults and strike slip for ZMP fault system, is justified. The convergence of plates in Eurasia and Iran, the velocity vector of eastern stations have smaller magnitude and it would be associated with adjacency of these stations and relatively stable block of Lute.

Shortening in the Zagros region is a well-known phenomenon. Based on the amounts of convergence and divergence that are determined, taking into account the LAMD station as the station in the southern end of the Zagros and stations MHAN, FDNG, SBAK, BAFT as stations in the Northeast Zagros, and the difference of velocity magnitude between these stations, shortening in the Zagros is obvious.

Weak points of determining the strain and the deformation analysis with geodetic observations are the heterogeneous distribution, lack of stations and lack of access to newer data. So the need for more permanent stations can be felt especially in important areas such as the Zagros for more detailed and applied studies. As were obtained in this study, the condition number 
in the regions where the density of stations is low, they have larger values than denser regions. For example ABDN and SHRZ stations (which are in the West region) have higher condition number.

\section{References}

Allmendinger R. W., Reilinger R., Loveless J., 2007: Strain and rotation rate from GPS in Tibet, Anatolia, and the Altiplano. Tectonics, 26, 3, TC3013, doi: 10.1029/2006 TC002030.

Bayer R., Shabanian E., Regard V., Doerflinger E., Abbassi M., Chery J., Nilforoushan F., Tatar M., Vernant P., Bellier O., 2003: Active deformation in the ZagrosMakran transition zone inferred from GPS measurements in the interval 2000-2002. Geophys. Res. Abstr., 5, 5891.

Byrne D. E., Sykes L. R., Davis D. M., 1992: Great thrust earthquakes and aseismicslip along the plate boundary of the Makran Subduction Zone. J. Geophys. Res., 97, B1, 449-478, doi: 10.1029/91JB02165.

Cai J., Grafarend E. W., 2007: Statistical analysis of geodetic deformation (strain rate) derived from the space geodetic measurements of BIFROST Project in Fennoscandia. J. Geodyn., 43, 2, 214-238, doi: 10.1016/j.jog.2006.09.010.

Hessami K., Nilforoushan F., Talbot C. J., 2006: Active deformation within the Zagros Mountains deduced from GPS measurements. J. Geol. Soc., 163, 1, 143-148, doi : 10.1144/0016-764905-031.

Jackson J., McKenzie D., 1984: Active tectonics of the Alpine-Himalayan belt between western Turkey and Pakistan. Geophys. J. Int. Roy. Astron. Soc., 77, 1, 185-264, doi: $10.1111 / j .1365-246 X .1984 . t b 01931 . x$.

Kashani I., Wielgosz P., Grejner-Brzezinska D. A., Mader G. L., 2008: A New NetworkBased Rapid - Static Module for the NGS Online Positioning User Service - OPUSRS. Navigation, 55, 3, 225-234, doi: 10.1002/j.2161-4296.2008.tb00432.x.

Lay T., Wallace T., 1995: Modern Global Seismology. Academic Press, United States, $521 \mathrm{p}$.

Masson F., Anvari M., Djamour Y., Walpersdorf A., Tavakoli F., Daignieres M., Nankali H., Van Gorp S., 2007: Large-scale velocity field and strain tensor in Iran inferred from GPS measurements: new insight for the present-day deformation pattern within NE Iran. Geophys. J. Int., 170, 1, 436-440, doi : 10.1111/j.1365-246X. 2007 $.03477 . \mathrm{x}$.

McCall G. J. H., 1997: The geotectonic history of the Makran and adjacent areas of southern Iran. J. Asian Earth Sci., 15, 6, 517-531, doi : 10.1016/S0743-9547 (97) 00032-9.

McClusky S., Reilinger R., Mahmoud S., Ben Sari D., Tealeb A., 2003: GPS constraints on Africa (Nubia) and Arabia plate motions. Geophys. J. Int., 155, 1, 126-138, doi : 10.1046/j.1365-246X.2003.02023.x.

McQuarrie N., 2004: Crustal scale geometry of the Zagros fold-thrust belt, Iran. J. Struct. Geol., 26, 3, 519-535, doi: 10.1016/j.jsg.2003.08.009. 
Mirzaei N., Gao M., Chen Y. T., 1998: Seismic source regionalization for seismic zoning of Iran: major seismotectonic provinces. J. Earthquake Predict. Res., 7, 465-495.

Molinaro M., Leturmy P., Guezou J.-C., Frizon de Lamotte D., Eshraghi S. A., 2005: The structure and kinematics of the south-eastern Zagros fold-thrust belt, Iran: From thin-skinned to thick-skinned tectonics. Tectonics, 24, 3, TC3007, doi: 10.1029/ $2004 \mathrm{TC} 001633$.

Regard V., Hatzfeld D., Molinaro M., Aubourg C., Bayer R., Bellier O., Yamini-Fard F., Peyret M., Abbasi M. R., 2010: The transition between Makran subduction and the Zagros collision: recent advances in its structure and active deformation. Geol. Soc. Spec. Publ., 330, 41-64, https://hal .archives-ouvertes.fr/hal-00356532, doi : $10.1144 /$ SP330.4.

Shen Z. K., Jackson D. D., Ge B. X., 1996: Crustal deformation across and beyond the Los Angeles basin from geodetic measurements. J. Geophys. Res., 101, B12, 27957-27980, doi : 10.1029/96JB02544.

Spakman W., Nyst M., 2002: Inversion of relative motion data for estimates of the velocity gradient field and fault slip. Earth Planet. Sci. Lett., 203,1, 577-591, doi : 10.1016/S0012-821X (02) 00844-0.

Tatar M., Hatzfeld D., Martinod J., Walpersdorf A., Ghafori-Ashtiany M., Chéry J., 2002: The present-day deformation of the central Zagros from GPS measurements. Geophys. Res. Lett., 29, 19, 33-1-33-4, doi: 10.1029/2002GL015427.

Vanicek P., Krakiwsky E., 1986: Geodesy: The Concepts. 2nd Edition, Elsevier Science, North-Holland, Amsterdam., 714 p.

Vernant P., Nilforoushan F., Hatzfeld D., Abbasi M. R., Vigny C., Masson F., Nankali H., Martinod J., Ashtiani A., Bayer R., Tavakoli F., Chéry J., 2004: Presentday crustal deformation and plate kinematics in Middle East constrained by GPS measurements in Iran and northern Oman. Geophys. J. Int., 157, 1, 381-398, doi : 10.1111/j.1365-246X. 2004.02222.x. 